\title{
AVALIAÇÃO DOS IMPACTOS AMBIENTAIS E SOCIAIS COMO SUBSÍDIO PARA LICENCIAMENTO AMBIENTAL DO PROJETO DE ASSENTAMENTO DE REFORMA AGRÁRIA MARIA BONITA I, POÇO REDONDO/SE ${ }^{1}$
}

\author{
EVALUATION OF THE ENVIRONMENTAL AND SOCIAL IMPACTS AS SUBSIDY \\ TO THE ENVIRONMENTAL LICENSING OF THE PROJECT OF LAND REFORM \\ SETTLEMENT MARIA BONITA I, POÇO REDONDO/SE
}

EVALUACIÓN DE IMPACTOS SOCIALES Y AMBIENTALES COMO SUBVENCIÓN PARA EL LICENCIAMIENTO AMBIENTAL DEL PROYECTO DE REFORMA AGRÁRIA MARIA BONITA I, POÇO REDONDO/SE

\author{
Thiago Almeida Leite - Universidade Federal de Sergipe - São Cristóvão - Sergipe - Brasil \\ thiagoal.se@gmail.com \\ Ivana Silva Sobral - Universidade Federal de Sergipe - São Cristóvão - Sergipe - Brasil \\ ivanasobral@yahoo.com.br
}

Karla Fernanda Barbosa Barreto - Universidade Federal de Sergipe - São Cristóvão - Sergipe - Brasil ibtsergipe@gmail.com

\section{Resumo}

0 presente trabalho identificou e avaliou os impactos ambientais e sociais negativos do projeto de assentamento de reforma agrária Maria Bonita I, localizado no município de Poço Redondo, Sergipe, visando a subsidiar o processo de licenciamento ambiental. Para tal, utilizaram-se duas matrizes: a primeira, adaptada de Leopold, foi usada para classificar qualitativamente os impactos de acordo com seu tipo, natureza, periodicidade, efeito, reversibilidade e alcance; e a segunda foi elaborada por esta pesquisa para listar as atividades impactantes, os impactos, suas respectivas medidas mitigadoras e os responsáveis em mitigá-las. Em seguida, as atividades impactantes foram descritas. Conclui-se que o licenciamento é de fundamental importância para minimizar os impactos ambientais e sociais e melhorar a qualidade de vida da população, uma vez que as condicionantes ambientais devem ser atendidas durante este processo.

Palavras-chave: impactos ambientais e sociais, licenciamento ambiental, matriz de Leopold, Poço Redondo.

\section{Abstract}

This study identified and evaluated the negative environmental and social impacts of the project of land reform settlement Maria Bonita I, located in the town of Poço Redondo, Sergipe, to support the licensing process. To this end, two matrices were used: the first, adapted from Leolpold, was used to classify the impacts qualitatively according to: its type, its nature, its timing, its effect, its reversibility and its range; and the second, was developed in this research to list the striking activities, impacts, mitigation measures and the responsible for mitigating them. Then, the striking activities were described. It was concluded that the licensing is essential to minimize the environmental and social impacts and improve the quality of life of the population, since the environmental conditions must be met during this process.

Key words: environmental and social impacts, environmental licensing, Leopold matrix, Poço Redondo. 
Resumen

Este estudio evaluó los impactos ambientales y sociales negativos del proyecto de la liquidación de la reforma agrária Maria Bonita I, ubicada en el municipio de Poço Redondo, Sergipe, destinado a apoyar el proceso de concesión de licencias ambientales. Para este fin, se utilizan dos matrices: la primera, adaptada a Leopold, fue utilizada para clasificar cualitativamente los impactos, de acuerdo com su tipo, su naturaleza, su periodicidad, su efecto, su reversibilidad y su alcance; y la segunda, fue desarollada por esta investigación para describir una lista de actividades de impacto, los impactos, sus respectivas medidas minimizadoras y los responsables para esta mitigación. Entonces, las actividades impactantes fueram descritas. Concluye que las licencias son de fundamental importancia para minimizar los impactos sociales y ambientales y mejorar la calidad de vida de la población, desde que las condiciones ambientales sean tratadas durante este proceso.

Palabras clave: impactos sociales y ambientales, licenciamiento ambiental, matrices de Leopold, Poço Redondo.

Introdução

O Brasil é um país com uma das maiores biodiversidade do planeta, responsável por aproximadamente 9,5\% de toda a biota da Terra (LEWINSOHN et al., 2005). Fruto de paisagens tão distintas, o país também é enriquecido pela diversidade cultural dos seus povos tais como ribeirinhos, trabalhadores rurais, quilombolas, índios, seringueiros, dentre tantos outros detentores de considerável conhecimento sobre o manejo dos recursos da biodiversidade brasileira.

$\mathrm{Na}$ zona rural brasileira, áreas naturais que prestam serviços ambientais - água, ar, alimento, energia, fitoterápicos, matéria-prima, lazer - tanto para as comunidades rurais e da floresta quanto para a população urbana são dizimadas para perpetuação do modelo capitalista de desenvolvimento, que não condiz com a realidade sociocultural dos povos do campo e da floresta. Com a degradação dos recursos naturais, meio de sobrevivência do homem do campo e da floresta, há o empobrecimento dos trabalhadores rurais e a perda de conhecimentos tradicionais.

A Caatinga é um bioma que ocorre exclusivamente no Brasil e ocupa cerca de $70 \%$ do território nordestino. Atualmente, ela se estende por oito estados do Nordeste (Ceará, Bahia, Sergipe, Alagoas, Pernambuco, Paraíba, Rio Grande do Norte e Piauí) e norte de Minas Gerais, cobrindo uma área de aproximadamente $800.000 \mathrm{~km}^{2}$ (MAJOR et al., 2004).

Apesar de estudos recentes terem demonstrado a importância da Caatinga para a conservação da biodiversidade brasileira, este bioma é o mais ameaçado atualmente devido à extração da madeira para uso energético e aos séculos de atividades agropastoris tradicionalmente não planejadas, nas quais o gado é criado de maneira extensiva e a agricultura é comumente nômade (a vegetação nativa é derrubada ou queimada, 
dando lugar a roças que serão abandonadas em poucos anos, em busca de novas áreas), fatores que resultaram na perda da vegetação nativa e na diminuição da fertilidade do solo.

Os impactos ambientais diretos e indiretos sobre a biodiversidade da Caatinga, resultantes da crescente ocupação humana, além da degradação de seus ambientes naturais remetem à grande perda nos serviços ambientais, dos quais as sociedades são altamente dependentes (GASTAL, 2002). Entende-se por impacto ambiental "qualquer alteração das propriedades físicas, químicas e biológicas do meio ambiente, causada por qualquer forma de matéria ou energia resultante das atividades humanas que, direta ou, indiretamente, afetam: a saúde, a segurança e o bem-estar da população; as atividades sociais e econômicas; a biota; as condições estéticas e sanitárias do meio ambiente" (CONAMA, 1986).

Estes impactos negativos causados na natureza podem ser minimizados através do processo de licenciamento ambiental, que, de acordo com a Lei n. 6.938, de 31 de agosto de 1981, tem como objetivo a preservação, melhoria e recuperação da qualidade ambiental propícia à vida, visando assegurar condições ao desenvolvimento socioeconômico, aos interesses da segurança nacional e à proteção da dignidade da vida humana.

O licenciamento ambiental é um processo exigido para a implantação de atividades causadoras de impactos ambientais. Trata-se de um processo prévio de controle ambiental para o exercício legal de atividades modificadoras do meio ambiente (CUNHA et al., 2005). O licenciamento ambiental de projetos de assentamento de reforma agrária tornou-se obrigatório a partir da Resolução do Conselho Nacional do Meio Ambiente - CONAMA n. 237/1997, que regulamentou os aspectos do licenciamento estabelecidos na Política Nacional do Meio Ambiente. Esta Resolução modificou o regime de licenciamento inaugurado pela Resolução CONAMA 001/1986, estabelecendo que todas as atividades potencialmente degradadoras ou poluidoras, e não somente aquelas que causem significativo impacto ambiental, deverão ser licenciadas pelo órgão ambiental competente (VAN ACKER, 1998).

Devido à grande abrangência da resolução CONAMA n. 237/1997, foi criada a Resolução CONAMA n. 289/2001, a primeira específica para licenciar assentamentos e que passou a exigir a obtenção da LP (Licença Prévia), seguida da LIO (Licença de Instalação e Operação). Posteriormente, com o intuito de flexibilizar e agilizar o processo, criouse a Resolução CONAMA n. 387/2006. No entanto, o número de licenças 
expedidas ainda é reduzido, comparado à quantidade de projetos de assentamentos existentes, podendo ser reflexo das dificuldades tanto técnicas e estruturais como também de caráter legal (SILVA et al., 2008).

Visando subsidiar o processo de licenciamento ambiental do projeto de assentamento de reforma agrária Maria Bonita I, localizado no município de Poço Redondo - Sergipe, esta pesquisa identificou e avaliou os impactos ambientais e sociais negativos; propôs medidas mitigadoras para minimizar e/ou cessar os impactos; e elencou os responsáveis em mitigá-los.

\section{Área de estudo}

O município de Poço Redondo está localizado na região noroeste do estado de Sergipe, limitando-se a nordeste com o estado de Alagoas, a sudoeste com o estado da Bahia, a sul e a leste com o município de Porto da Folha e a oeste e norte com Canindé do São Francisco. A sede municipal tem 210 metros de altitude e coordenadas geográficas de $09^{\circ}$ 48' 17'de latitude sul e $37^{\circ} 41^{\prime} 06^{\prime}$ ' de longitude oeste (BOMFIM et al., 2002). O projeto de assentamento de reforma agrária Maria Bonita I está

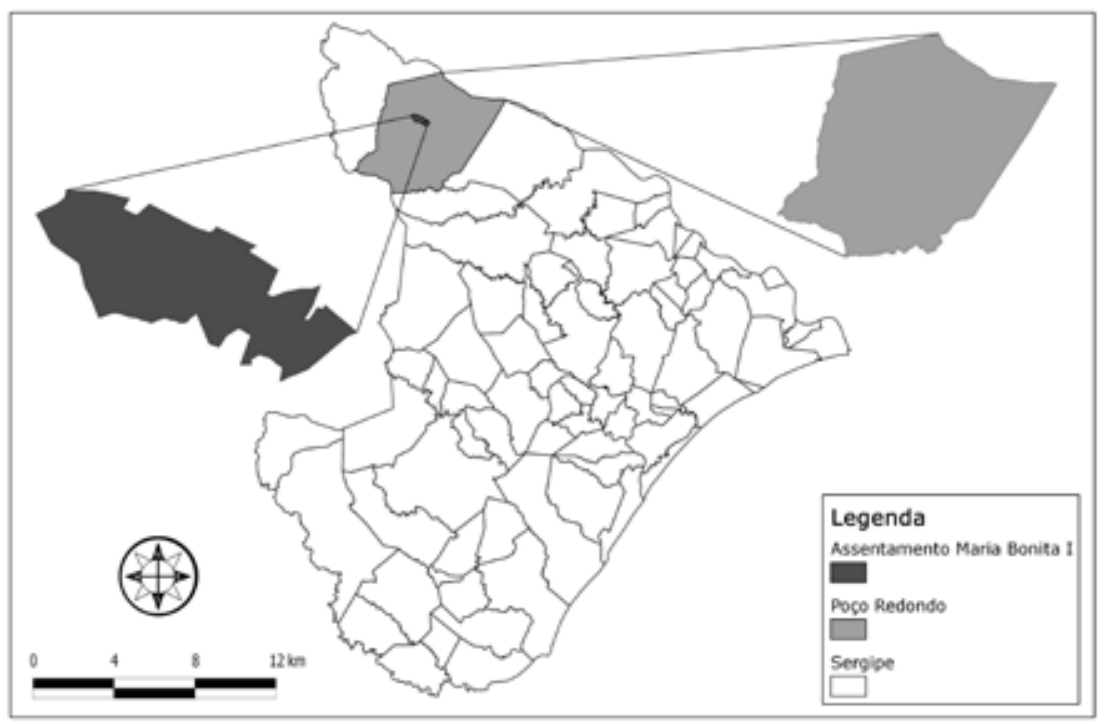

Figura 1- Localização do projeto de assentamento de reforma agrária Maria Bonita I. 
situado no município de Poço Redondo, sertão sergipano (Figura 1). Para elaboração da Figura 1, através do software Quantum GIS na sua versão 1.5.0, utilizaram-se mapas temáticos digitais de assentamentos rurais, municípios e estados (SERGIPE, 2004).

\section{Metodologia}

Este trabalho foi elaborado entre julho e setembro de 2010 por meio de pesquisas documentais e de campo. Durante as pesquisas, foram realizados estudos documentais, estruturação da pesquisa e sistematização dos dados. Na etapa de campo, realizaram-se identificação e avaliação dos impactos sociais e ambientais. Os sujeitos desta pesquisa foram os trabalhadores rurais do assentamento de reforma agrária Maria Bonita I, cujas participações foram essenciais para a construção deste trabalho sob a ótica de quem vivencia o local da pesquisa.

Para a identificação e avaliação dos impactos ambientais e sociais negativos duas matrizes foram utilizadas: a primeira, adaptada de Leolpold, foi usada para classificar qualitativamente os impactos de acordo com: seu tipo, sua natureza, sua periodicidade, seu efeito, sua reversibilidade e seu alcance (Quadro 1); a segunda foi elaborada por esta pesquisa para identificar as atividades impactantes, os impactos, suas respectivas medidas mitigadoras e os responsáveis em mitigá-las (Quadro 2).

A matriz de Leopold, apesar de ter sido elaborada para qualificar os impactos ambientais, foi adaptada, nesta pesquisa, para classificar também os impactos sociais. Tal matriz foi escolhida por possibilitar uma análise sistêmica dos problemas ambientais e sociais já existentes. Nela foram identificados os impactos, as atividades impactantes e os atributos ambientais: meio físico (água, ar e solo), meio biótico (fauna e flora), meio antrópico (socioeconômico e infraestrutura); para posteriormente analisar qualitativamente os impactos conforme as características a seguir (SANTOS, 2009):

Tipo: o impacto é positivo quando causa algum benefício a algum fator ambiental; ou negativo quando alguma atividade impactante causa dano à qualidade de algum fator ambiental.

Natureza: o impacto é direto quando é resultante de alguma relação de causa e efeito; ou indireto, quando é resultante de alguma ação secundária ou de vários seguimentos de reações. 


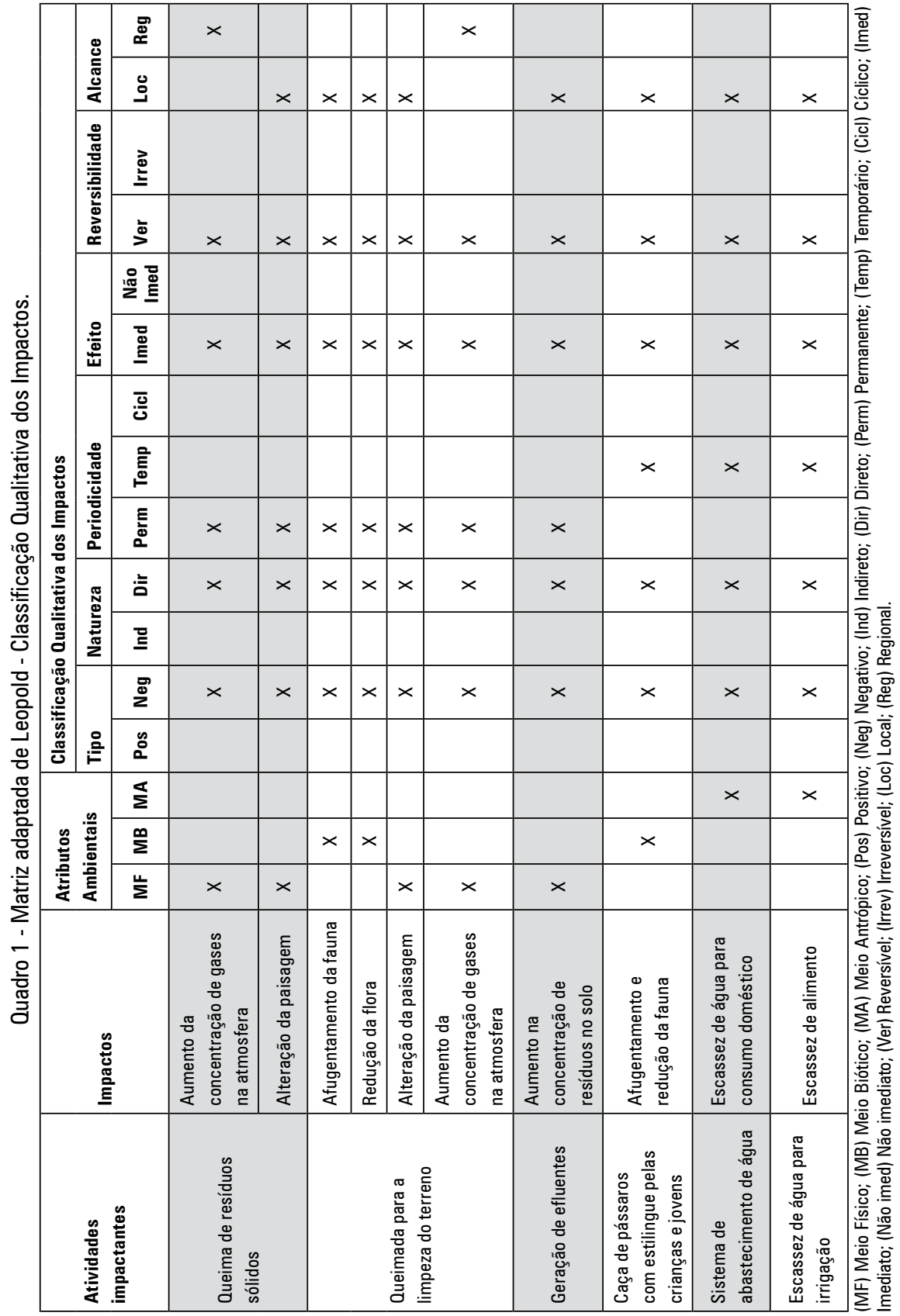


Quadro 2- Matriz de impactos e medidas mitigadoras do projeto de assentamento de reforma agrária Maria Bonita I, localizado no município de Poço Redondo, Sergipe.

\begin{tabular}{|c|c|c|c|}
\hline Atividades & Impactos & Medidas Mitigadoras & $\begin{array}{l}\text { Responsáveis pelas } \\
\text { medidas }\end{array}$ \\
\hline \multirow{2}{*}{$\begin{array}{l}\text { Queima de resíduos } \\
\text { sólidos }\end{array}$} & $\begin{array}{l}\text { Aumento da concentração } \\
\text { de gases na atmosfera }\end{array}$ & \multirow{2}{*}{$\begin{array}{l}\text { Coleta de lixo pela } \\
\text { prefeitura }\end{array}$} & \multirow{2}{*}{$\begin{array}{l}\text { Prefeitura de Poço } \\
\text { Redondo }\end{array}$} \\
\hline & Alteração da paisagem & & \\
\hline \multirow{4}{*}{$\begin{array}{l}\text { Queimada para a } \\
\text { limpeza do terreno }\end{array}$} & Afugentamento da fauna & \multirow{4}{*}{$\begin{array}{l}\text { Palestra sobre o manejo } \\
\text { ecológico do solo com } \\
\text { jovens e adultos }\end{array}$} & \multirow{4}{*}{ INCRA e ONG's } \\
\hline & Redução da flora & & \\
\hline & Alteração da paisagem & & \\
\hline & $\begin{array}{l}\text { Aumento da concentração } \\
\text { de gases na atmosfera }\end{array}$ & & \\
\hline $\begin{array}{l}\text { Geração de } \\
\text { efluentes }\end{array}$ & $\begin{array}{l}\text { Aumento na concentração } \\
\text { de resíduos no solo }\end{array}$ & $\begin{array}{l}\text { Tanque séptico e vala de } \\
\text { infiltração }\end{array}$ & INCRA \\
\hline $\begin{array}{l}\text { Caça de pássaros } \\
\text { com estilingue pelas } \\
\text { crianças e jovens }\end{array}$ & $\begin{array}{l}\text { Afugentamento e redução } \\
\text { da fauna }\end{array}$ & $\begin{array}{l}\text { Palestras sobre } \\
\text { a importância da } \\
\text { biodiversidade com as } \\
\text { crianças e jovens }\end{array}$ & INCRA \\
\hline $\begin{array}{l}\text { Sistema de } \\
\text { abastecimento de } \\
\text { água }\end{array}$ & $\begin{array}{l}\text { Escassez de água para } \\
\text { consumo doméstico }\end{array}$ & $\begin{array}{l}\text { Criação de um Sistema de } \\
\text { abastecimento de água }\end{array}$ & $\begin{array}{l}0 \text { sistema de } \\
\text { abastecimento de água } \\
\text { encontra-se em fase } \\
\text { de implementação pela } \\
\text { Chesf }\end{array}$ \\
\hline $\begin{array}{l}\text { Escassez de água } \\
\text { para irrigação }\end{array}$ & Escassez de alimento & $\begin{array}{l}\text { Perfuração de poços } \\
\text { artesianos }\end{array}$ & Governos e ONG's \\
\hline
\end{tabular}

Periodicidade: o impacto é temporário quando o efeito se manifesta por um determinado tempo, após realização da ação; ou cíclico quando o efeito se faz sentir em determinados períodos (ciclos); ou permanente quando determinada ação se concretiza, sendo os efeitos manifestados por um período não determinado.

Efeito: o impacto é imediato quando se manifesta simultaneamente à ação que o gera; ou não imediato quando ocorre depois de certo tempo, podendo ser constatado em dias, meses ou anos.

Reversibilidade: o impacto é reversível quando dado ambiente, ao sofrer uma ação, retorna às suas condições originais; ou irreversível quando o ambiente ao sofrer a ação do impacto, não retorna às condições originais.

Alcance: o impacto é local quando seus efeitos se manifestam na própria localidade e nas imediações da ação do impacto; ou regional quando a 
ação e, consequentemente, seus efeitos são refletidos além da fronteira onde os impactos foram provocados.

\section{Resultados e discussão}

Durante as décadas de 1960 e 1970, a Revolução Verde foi imposta aos países menos desenvolvidos com a promessa de diminuir a fome de sua população através do aumento da produção agrícola por meio de sementes melhoradas, insumos industriais, mecanização e diminuição do custo de manejo. Mas, contraditoriamente, além de não resolver o problema da fome, aumentou a concentração fundiária, a dependência de sementes modificadas, a destruição ambiental e a precarização do trabalho do homem do campo. De acordo com Santos (2003), a Revolução Verde também transformou os processos tradicionais de comercialização e criou as condições para a instalação de grandes monopólios importadoresexportadores, muitos dos quais são subsidiários de firmas multinacionais. E, naturalmente, ela também desorganizou o padrão tradicional de propriedade da terra, com o desenvolvimento de empresas agrícolas capitalistas à custa de pequenos proprietários (SANTOS, 2003).

Os projetos de assentamentos de reforma agrária, além de garantir a dignidade e cidadania da comunidade, são instrumentos que asseguram a função social da terra e encontram-se intimamente ligados ao fato de que a propriedade rural é essencial e indispensável à segurança alimentar da sociedade no interesse do estado, inclusive da própria humanidade.

A conservação da natureza e a equidade social são fundamentais para o desenvolvimento sustentável dos projetos de assentamentos. Assegurar e garantir que as medidas preventivas e de controle à conservação dos recursos naturais sejam compatíveis com o desenvolvimento sustentável estão entre os principais objetivos do licenciamento ambiental (XIMENES et al., 2008).

Visando o licenciamento ambiental e a melhoria da qualidade de vida da comunidade rural do projeto de assentamento Maria Bonita I, os impactos negativos foram identificados e avaliados qualitativamente de acordo com o tipo, a natureza, a periodicidade, o efeito, a reversibilidade e o alcance (Quadro 1); medidas mitigadoras foram propostas e os responsáveis em executá-las foram identificados (Quadro 2). 
Artigo

\section{Queima de resíduos sólidos}

Os moradores da região queimam os resíduos sólidos, pois não há sistema de coleta da prefeitura. Esta queima ocasiona alguns impactos no meio físico, como o aumento da concentração de gases na atmosfera e a alteração da paisagem. De acordo com a Lei 12.305, de 2 de agosto de 2010, cabe à Prefeitura de Poço Redondo, a elaboração do plano municipal de gestão integrada de resíduos sólidos, para terem acesso a recursos da União, e assim efetuarem a limpeza e o manejo dos resíduos sólidos.

O impacto "aumento da concentração de gases na atmosfera" é classificado como negativo, direto, permanente, imediato, reversível e regional. Já o impacto "alteração da paisagem” é classificado como negativo, direto, permanente, imediato, reversível e local.

Para minimizar as consequências decorrentes desta atividade impactante, sugere-se que a associação de moradores do assentamento se mobilize e entre em contato com a Prefeitura de Poço Redondo.

\section{Queimada para a limpeza do terreno}

As queimadas para limpeza do terreno são efetuadas pelos assentados devido à facilidade e rapidez do fogo para tal tarefa, causando, ao meio físico, uma alteração negativa na paisagem, como também aumentando a concentração de gases na atmosfera, interferindo assim na qualidade do ar. Além disso, esse procedimento interfere no meio biótico, acarretando o afugentamento da fauna e redução da flora e, consequentemente, da base genética (SOBRAL et al., 2007).

Os impactos "alteração da paisagem”, "redução da flora”, "redução da base genética", "afugentamento e redução da fauna" são classificados como negativos, diretos, permanentes, imediatos, reversíveis e locais. Já o impacto "aumento da concentração dos gases na atmosfera" é classificado como negativo, direto, permanente, imediato, reversível e regional. Para mitigar as consequências decorrentes desta ação impactante, sugere-se que o INCRA (Instituto Nacional de Colonização e Reforma Agrária), por meio da assistência técnica, organize palestras para jovens e adultos sobre a importância do manejo ecológico do solo. 


\section{Geração de efluentes}

A geração de efluentes, advinda da falta de saneamento básico adequado, provoca no meio físico um aumento na concentração de resíduos no solo. Estes resíduos podem contaminar o lençol freático e o solo, através das substâncias que degradam o meio ambiente. No projeto de assentamento Maria Bonita I, os efluentes são destinados para fossas negras, que, de acordo com Novaes et al. (2002), podem contaminar as águas subterrâneas.

O impacto "aumento na concentração de resíduos no solo" é classificado como negativo, direto, permanente, imediato, reversível e local. Para reverter os impactos negativos decorrentes desta ação impactante, sugere-se que o INCRA contrate uma empresa para a construção de tanque séptico e vala de infiltração.

\section{Caça de pássaros com estilingue pelas crianças e jovens}

A fauna silvestre é importante na manutenção do equilíbrio dos ecossistemas naturais. A capacidade reprodutiva e a sobrevivência de muitas espécies vegetais dependem das relações animal - vegetal. Assim, a caça como forma de diversão das crianças e jovens é um problema, pois causa o afugentamento e a redução da fauna, podendo, se em grande proporção, acarretar a extinção de espécies (SOBRAL et al., 2007). Os impactos relacionados à caça de pássaros com estilingue pelas crianças e jovens são classificados como negativos, diretos, temporários, imediatos, reversíveis e locais. Para mitigar este impacto, sugere-se a sensibilização dos caçadores por meio de palestras sobre a importância da biodiversidade.

\section{Sistema de abastecimento de água}

Segundo Tucci (2004), a água é um bem relevante que deve ser utilizado pelo homem para sua sobrevivência e melhoria de suas condições econômicas, sociais e comunitárias. A escassez de água para o consumo doméstico observada na região afeta o meio antrópico e poderá ser cessada com criação do sistema de abastecimento de água, que, de acordo com os assentados, se encontra em fase de implantação pela Companhia Hidroelétrica do São Francisco - CHESF. O impacto "escassez de água para 
o consumo doméstico" é classificado como: negativo, direto, temporário, imediato, reversível e local.

\section{Escassez de água para irrigação}

A falta de água para irrigação é uma dificuldade vivenciada pelas famílias situadas no assentamento Maria Bonita I. Esta situação poderá ser mitigada com a perfuração de poços artesianos para a irrigação de hortas e pomares comunitários, incentivando assim a agricultura familiar. Segundo Santiago et al. (2009), a agricultura familiar nordestina é responsável pela produção dos principais alimentos consumidos pelos brasileiros, tais como, arroz, feijão, mandioca e milho. No meio antrópico, o impacto "escassez de alimento" é classificado como negativo, direto, temporário, imediato, reversível e local.

\section{Considerações finais}

As ações ambientais impactantes estão relacionadas aos problemas sociais, uma vez que muitos dos impactos no meio ambiente, tais como queima dos resíduos sólidos, geração de efluentes; caça com estilingue acontecem porque não há condições básicas para a sobrevivência das famílias, relacionadas a infraestrutura e saneamento básico.

O processo de licenciamento é de fundamental importância para minimizar os impactos ambientais e sociais, pois os seus principais objetivos são assegurar e garantir que as medidas preventivas e de controle à conservação dos recursos naturais sejam compatíveis com o desenvolvimento sustentável.

Para que os impactos ambientais e sociais sejam minimizados é necessária a mobilização da comunidade, das instituições governamentais e não governamentais em prol da melhoria da qualidade de vida das famílias do Projeto de Assentamento Maria Bonita I, estimulando, consequentemente, a fixação dos assentados no campo.

\section{Nota}

1. Esta pesquisa foi elaborada durante a execução do convênio INCRA/BIOTERRA n. 11000/2008, que tratou dos estudos ambientais de 32 projetos de assentamentos de reforma agrária do Sertão Sergipano, para fins de licenciamento ambiental. 


\section{Referências}

BRASIL. Casa Civil da Presidência da República. Lei n. 6.938, de 31 de agosto de 1981. Dispõe sobre a Política Nacional do Meio Ambiente, seus fins e mecanismos de formulação e aplicação, e dá outras providências. Disponível em: <http://www. mma.gov.br/port/conama/legiabre.cfm?codlegi=313>. Acesso em: 31 out. 2010.

BRASIL. Casa Civil da Presidência da República. Lei n. 12.305, de 2 de agosto de 2010. Institui a Política Nacional de Resíduos Sólidos; altera a Lei n. 9.605, de 12 de fevereiro de 1998; e dá outras providências. Disponível em: <http://www.mma. gov.br/port/ conama/legiabre.cfm?codlegi=636>. Acesso em: 31 out. 2010.

CONAMA - Conselho Nacional do Meio Ambiente. Ministério do Meio Ambiente. Resolução n. 001/86, de 23 de janeiro de 1986. Dispõe sobre critérios básicos e diretrizes gerais para a avaliação de impacto ambiental. Disponível em: <http:// www.mma.gov.br/port/conama/legiabre.cfm?codlegi=23>. Acesso em: 31 out. 2010.

CONAMA - Conselho Nacional do Meio Ambiente. Ministério do Meio Ambiente. Resolução n. 237/97, de 19 de dezembro de 1997. Dispõe sobre a revisão e complementação dos procedimentos e critérios utilizados para o licenciamento ambiental. Disponível em: <http://www.mma.gov.br/port/conama/legiabre.cfm? codlegi=237>. Acesso em: 31 out. 2010.

CONAMA - Conselho Nacional do Meio Ambiente. Ministério do Meio Ambiente. Resolução n. 289/01, de 25 de outubro de 2001. Estabelece diretrizes para o Licenciamento Ambiental de Projetos de Assentamentos de Reforma Agrária. Disponível em: <http://www.mma.gov.br/port/conama/legiabre.cfm? codlegi=286 $>$. Acesso em: 31 out. 2010.

CONAMA - Conselho Nacional do Meio Ambiente. Ministério do Meio Ambiente. Resolução n. 387/06, de 29 de dezembro de 2006. Estabelece procedimentos para o licenciamento ambiental de Projetos de Assentamentos de Reforma Agrária, e dá outras providências. Disponível em: <http://www.mma.gov.br/port/conama/ legiabre.cfm? codlegi=525>. Acesso em: 31 out. 2010.

BOMFIM, L. F. C.; COSTA, I. V. G.; BENVENUTI, S. M. P. Projeto cadastro da infraestrutura hídrica do Nordeste. Diagnóstico do Município de Poço Redondo. Aracaju: CPRM, 2002.

CUNHA, S. B.; GUERRA, A. J. T. Avaliação e perícia ambiental. 6. ed. Rio de Janeiro: Bertrand Brasil, 2005.

GASTAL, M. L. Os instrumentos para a conservação da biodiversidade. In: BENSUNSAN, N. (Org.). Seria melhor mandar ladrilhar? Biodiversidade como, para que, por quê. Brasília: UNB/ISA, 2002. p. 29-41.

LEWINSOHN, T. M.; PRADO, P. I. Quantas espécies há no Brasil? Megadiversidade, Belo Horizonte, v. 1, n. 1, p. 36-42, 2005.

MAJOR, I.; SALES, J. R, L. G.; CASTRO, R. Aves da Caatinga/Birds of the Caatinga. 1. ed. Fortaleza: Edições Demócrito Rocha, Associação Caatinga, 2004.

NOVAES, A. P. et al. Utilização de uma Fossa Séptica Biodigestora para Melhoria do Saneamento Rural e Desenvolvimento da Agricultura Orgânica. São Carlos: Embrapa Instrumentação Agropecuária, n. 46, 2002. 
SANTIAGO, D. F. et al. Comportamento dos Indicadores Agrícolas das Principais Lavouras Beneficiadas pelo PRONAF na Região Nordeste. In: Anais do Congresso Desenvolvimento Rural e Sistemas Agroalimentares: os Agronegócios no Contexto de integração das Nações. Sociedade Brasileira de Economia, Administração e Sociologia Rural, 47. Porto Alegre: SOBER, 2009.

SANTOS, L. I. C. Identificação dos impactos ambientais na Área de Proteção Ambiental Morro do Urubu. Aracaju: UFS, 2009.

SANTOS, M. Economia espacial: críticas e alternativas. 2. ed. São Paulo: Edusp, 2003.

SERGIPE. Superintendência de Recursos Hídricos. Atlas Digital sobre os Recursos Hídricos de Sergipe. Aracaju: SEPLANTEC-SRH, 2004. CD-ROM.

SILVA, R. P.; ARRAES, N. A. M.; VILELA FILHO, L. R. O processo de licenciamento ambiental em áreas de assentamento no estado de São Paulo. Campinas: FEAGRI/ Unicamp, 2008.

SOBRAL, I. S. Avaliação dos impactos ambientais no Parque Nacional Serra de Itabaiana - SE. Revista Caminho de Geografia, Uberlândia, Minas Gerais, v. 8, n. 24, p. 102-110, 2007.

TUCCI, C. E. M. Hidrologia: ciência e aplicação. 3. ed. Porto Alegre: Ed. UFRGS/ ABRH, 2004.

VAN ACKER, F. T. Os estudos de impacto ambiental: da Resolução 1/86 à Resolução 237/97 do CONAMA. In: Avaliação de Impacto Ambiental. São Paulo: Secretaria do Meio Ambiente, 1998. p. 25-29.

XIMENES, I. F.; MAIA, M. J. C.; LIMA, C. S. Estudo de impacto ambiental em áreas de assentamento rural: uma avaliação do passivo ambiental do Projeto de Assentamento Porto Alonso. In: Anais do Congresso da Sociedade Brasileira de Economia, Administração e Sociologia Rural, 46. Rio Branco: UFAC, 2008.

Thiago Almeida Leite - Graduando em Engenharia Florestal pela Universidade Federal de Sergipe.

Ivana Silva Sobral - Mestre em Agroecossitemas pela Universidade Federal de Sergipe. Doutoranda em Geografia pela Universidade Federal de Sergipe.

Karla Fernanda Barbosa Barreto - Mestre em Desenvolvimento e Meio Ambiente pela Universidade Federal de Sergipe. 